\title{
ROLE OF ALPHA BLOCKER IN URETERORENOSCOPY
}

\author{
Aamer Nadeem, Noreen Anwar*, Naveed Ahmed, Yasser Saeed Khan**, Irum Rashid, Mujahid Zulfiqar Ali \\ Combined Military Hospital Quetta/National University of Medical Sciences (NUMS) Pakistan, *Quetta Institute of Medical Sciences, Quetta/National University \\ of Medical Sciences (NUMS) Pakistan, ${ }^{* *}$ Combined Military Hospital Sialkot/National University of Medical Sciences (NUMS) Pakistan
}

\section{ABSTRACT}

Objective: To determine the efficacy of alpha blockers in successful management of lower and mid ureteral stones by ureterorenoscopy.

Study Design: Comparative prospective study.

Place and Duration of Study: Department of Urology, Combined Military Hospital Quetta Pakistan, from Jul 2018 to Dec 2019. Methodology: Total of 150 patients having mid and lower ureteric calculi requiring ureterorenoscopy were divided into two groups. Group A included patients without pre-treatment with alpha blocker was administered before they were subjected to ureterorenoscopy. Study group B included patients who received daily oral dose of alpha blocker, Tamsulosin 0.4 $\mathrm{mg}$ twice daily, for 1 week before ureterorenoscopy. Per-operative findings in both the groups were recorded. Results were analyzed by comparing the outcome between both groups in terms of ease of performing procedure, duration of procedure, complications, duration of hospital stay and need for stent placement.

Results: Mean operative time was significantly shorter in group B as compared to group A, $(15.9 \pm 3.81$ min vs. $21.9 \pm 3.63$ min; $p \leq 0.001)$. Demographic and stone characteristics were comparable between the both groups. Success rate was $74(98.7 \%)$, in group B as compared to $68(90.7 \%)$ in group A, with statistically significant difference $(p=0.020)$. Complications in group B were less frequent $1(1.3 \%)$ vs $7(9.3 \%)$ in group A ( $p$-value $=0.027)$.

Conclusion: Use of alpha blockers for one week before performing ureterorenoscopy resulted in fewer complications and made the procedure easier to perform as well.

Keywords: Tamsulosin, Ureteroscopy, Ureteral calculi.

How to Cite This Article: Nadeem A, Anwar N, Ahmed N, Khan YS, Rashid I, Ali MZ. Role of Alpha Blocker in Ureterorenoscopy. Pak Armed Forces Med J 2021; 71(6): 2033-2036. Doi: https://doi.org/10.51253/pafmj.v6i6.5647

\footnotetext{
This is an Open Access article distributed under the terms of the Creative Commons Attribution License (https://creativecommons.org/licenses/by-nc/4.0/), which permits unrestricted use, distribution, and reproduction in any medium, provided the original work is properly cited.
}

\section{INTRODUCTION}

Stone in the ureter generally comes from the kidney. Mostly the ureteric calculus is single and small $\pm 5 \mathrm{~mm}$ ) is expected to pass spontaneously. It is a major cause of acute abdomen and patient presents with colicky abdominal pain and microscopic haematuria. Patient is initially treated with analgesics followed by intervention depending upon the size of the calculus. The role of conservative treatment of ureteric calculi in expulsion of uncomplicated less than $5 \mathrm{~mm}$ size stones is well established. ${ }^{1}$ In this case, progress of stone is followed clinically and with radiographs every 3-6 weeks along with the symptoms of the patient. Depending upon the location and size of calculus, a variety of treatment options have been implicated in the treatment of ureteric calculi like removal with dormia basket, ureteric meatotomy, push bang followed by extracorporeal shock wave lithotripsy, ureterolithotomy and ureterorenoscopy. Ureterorenoscopy (URS) is commonly performed procedure for management of

Correspondence: Dr Aamer Nadeem, Classified Surgeon/Urologist, Department of Surgical, CMH Quetta-Pakistan

Received: 08 Nov 2020; revision received: 26 Apr 2021; accepted: 03 May 2021 upper and lower ureteral stones with a long thin endoscope passed transurethrally across the bladder into the ureter. URS has some complications as well with an overall complication rate of $9-11 \%$ including avulsion of ureteric urothelium, perforation of ureter, instrument impaction, ureteric laceration, stone extravasation, bleeding and rarely ureteric stricture. ${ }^{2}$ This may end up in a second procedure for stone removal and hence increase the morbidity. ${ }^{3}$ A lot of work has been done in order to improve the treatment of ureteric calculi by URS; a variety of instruments have been introduced and modifications have also been done. ${ }^{4} \mathrm{Adv}-$ ancements in URS techniques like improved optical performance from ureteroscopes with in-built digital cameras at their distal end, the so-called 'chip at the tip', and improved extraction baskets have definitely improved the stone free period. So, URS is expected to continue to improve in both ease and safety in the future. Likewise, introduction of alpha blockers and calcium channel blockers before URS has dramatically increased the incidence of spontaneous passage of calculi. ${ }^{5}$ The use of these drugs, especially alpha blockers, as pre-treatment, has also helped in performing URS with more ease. 
We have selected Tamsulosin which is a selective a-1 adrenoceptor antagonist. This drug inhibits contraction of ureteral musculature, reduces basal tone, decreases frequency of peristalsis and amplitude along with intraluminal pressure; hence it is best suited for our study. It is easily available and cost effective at the same time. ${ }^{6-9}$ The rationale of this study is to see the effect of alpha blockers on successful removal of stone. We have hypothesized that pre-treatment with alpha blocker, Tamsulosin, should facilitate the procedure of URS keeping in view its mechanism of action.

\section{METHODOLGY}

It was a comparative prospective study conducted at the department of Urology, Combined Military Hospital Quetta, from July 2018 to December 2019. Total 150 patients were included in the study, with 75 patients in each group A and B through nonprobability consecutive sampling.

Inclusion Criteria:All adult patients, more than 18 years old, with radiopaque stone with size $8 \mathrm{~mm}-15 \mathrm{~mm}$ were included in the study.

Exclusion Criteria:Patients with pregnancy, bilateral stones/high grade hydronephrosis, drug allergy to Tamsulosin, previous ureteral surgery either by endoscopy or open surgery, renal failure were excluded from the study.

Operative timewas taken as time from introduction of ureteroscope till the end of procedure. Complications of the procedure were divided into major and minor based on Clavien Dindo classification system. Grade I injuries were considered minor complications included all events without adverse outcome like mucosal injuries, haematuria, urine retention and mechanical failure. Grade II and III injuries were considered major complications like need for transfusion, urinary tract infection, need for second procedure, urosepsis, multi organ dysfunction, myocardial infarction and renal failure.

The study was conducted after taking approval from ethical committee of CMH Quetta, letter number 23-05/READ-IRB/2020 dated 25th October 2020. Written and informed consent was taken from all patients. After detailed history and clinical examination necessary laboratory and radiological investigations were done. These included urine analysis, urine culture, blood urea and serum creatinine, complete blood cell count, liver function tests, hepatitis serology and coagulation profile. In addition, initiallyultrasonography followed byComputed Tomography KUB with stone protocol were also performed in all patients. After investigations, patients having middle and lower ureteric calculi were planned for URS and given appointment accordingly and allocated group through lottery method. Members of control group "A" received only analgesics and antibiotics before URS whereas study group " $\mathrm{B}$ " received a daily oral dose of Tamsulosin 0.4 mg twice daily for one week before URS. This was a double blind study. The treating surgeon did not know about the group patient belonged to.

Under spinal or general anesthesia, a guidewire was passed, size 0.032, through ureteric orifice into ureter, confirmed with fluoroscope. URS Richard Wolf $7.5 \mathrm{Fr}$ with graduated narrow tip was negotiated over the guidewire to identify the ureteral orifice. Hydrodilatation of ureter wasfacilitated by water pump incorporated in continuous irrigation system. The stone was then fragmented with pneumatic lithoclast or electromagnetic lithorapid (Olympus). After complete fragmentation of stone, evacuation of the gravel was facilitated with the help of water pump system. DJ stent 4.7 French was used in cases where indicated for 3-6 weeks. Disintegration was performed using the Swiss pneumatic lithoclast, and the stone gravel was retrieved using a grasper forceps to ensure removal of all sizable gravel. Perioperative antibiotics and analgesics were used in all cases. Operative time was noted starting from insertion of the guide wire into the urethra till the removal of the stone gravel and documented on a prescribed proforma. Patients were discharged depending upon the individual response and any complication encountered per-operatively and duration of hospital stay was also documented.

Follow up of the patients was scheduled at 2nd week and an X-Ray KUB was performed to exclude residual stone and thus defining success of treatment.

Data analysis was performed using the software programme Statistical Package for the social sciences (SPSS) version 22. The t-test and the Mann-Whitney test were used for comparison of the numerical variables. The categorical variables were compared using the chi-square and Fisher exact test. The $p$-value of $\leq 0.05$ was considered as significant.

\section{RESULTS}

A total of 150 patients were included in the study and then divided into two equal groups " $A$ " and " $B$ ". In group " $A$ " no alpha blockers were given before URS while in group " $\mathrm{B}$ " Tamsulosin was used to achieve alpha blockade before performing URS. Mean age was $35.4 \pm 13.4$ years. Stone size in both groups was similar 
i.e. $13.6 \mathrm{~mm}$ in group " $\mathrm{A}$ " vs $13.4 \mathrm{~mm}$ in group " $\mathrm{B}$ " ( $p$ value 0.079). Left sided stone disease was more frequent as compared to right sided one i.e. $79(52.7 \%)$ vs $71(49.3 \%)$. There was a significant difference in operative times between two groups. Group " $A$ "had a time of $21.9 \pm 3.63 \mathrm{~min}$ while group " $\mathrm{B}$ " had a time of $15.9 \pm 3.81 \mathrm{~min}, p<0.001$.

It is quite evident from the results mentioned in Table that success rate was high in study group " $\mathrm{B}$ " (74 $(98.7 \%)$ as compared to $68(90.7 \%)$ in group " $\mathrm{A}$ ") with $p$-value $=0.020$. Similarly, far better results were seen in group " $B$ " patients in terms of lesser hospital stay, minimal complications and operative time. There were $7(9.3 \%)$ major complications in group " $\mathrm{A}$ " resulting in failure of treatment. Stone migration occurred in $3(4 \%)$ patients, perforation and need for blood transfusion in one and in remaining $3(4 \%)$ patients guide wire could not be passed. Similarly, there were 6 minor complications in group " $\mathrm{A}$ ", $3(4 \%)$ had urinary tract infection and the other three had mild haematuria. Complications in group " $\mathrm{B}$ " were less frequent. One $(1.3 \%))$ vs 7 $(9.3 \%)$ in group " $\mathrm{A}$ " ( $p$-value $=0.027)$. Only one patient had treatment failure and another patient developed urinary tract infection in post-operative period which responded well to antibiotics.

Table: Intra-operative characteristics of patients.

\begin{tabular}{|c|c|c|c|c|}
\hline Parameters & Catagories & $\begin{array}{c}\text { group A } \\
\text { (control) } \\
(n=75)\end{array}$ & $\begin{array}{c}\text { group B } \\
\text { (study) } \\
(n=75)\end{array}$ & $\begin{array}{c}p- \\
\text { value }\end{array}$ \\
\hline $\begin{array}{l}\text { Operation } \\
\text { time (min) }\end{array}$ & & $\begin{array}{c}21.9 \pm \\
3.63\end{array}$ & $\begin{array}{c}15.9 \pm \\
3.81\end{array}$ & $<0.001$ \\
\hline \multicolumn{5}{|c|}{ Complications n (\%) } \\
\hline $\begin{array}{l}\text { (As per } \\
\text { Clavien } \\
\text { Dindo } \\
\text { classification) }\end{array}$ & $\begin{array}{c}\text { Major } \\
\text { Minor } \\
\text { No } \\
\text { complications } \\
\end{array}$ & $\begin{array}{c}7(9.3) \\
6(8) \\
62(82.7) \\
\end{array}$ & $\begin{array}{l}1(1.3) \\
2(2.7) \\
72(96) \\
\end{array}$ & 0.027 \\
\hline $\begin{array}{l}\text { Hospital stay } \\
\text { (days) }\end{array}$ & & $\begin{array}{c}1.33 \pm \\
0.90\end{array}$ & $\begin{array}{c}1.16 \pm \\
0.65 \\
\end{array}$ & 0.010 \\
\hline $\begin{array}{l}\text { Ureteral } \\
\text { stenting n (\%) }\end{array}$ & $\begin{array}{c}\text { Stenting } \\
\text { No stenting }\end{array}$ & $\begin{array}{c}8(10.7) \\
67(89.3)\end{array}$ & $\begin{array}{c}3(4) \\
72(96)\end{array}$ & 0.110 \\
\hline $\begin{array}{l}\text { Outcome } \\
\mathrm{n}(\%)\end{array}$ & $\begin{array}{l}\text { Success } \\
\text { Failed }\end{array}$ & $\begin{array}{c}68(90.7) \\
7(9.3)\end{array}$ & $\begin{array}{c}74(98.7) \\
1(1.3)\end{array}$ & 0.020 \\
\hline
\end{tabular}

\section{DISCUSSION}

Management of renal and ureteric stones has changed and improved overtime and open surgery has been replaced by minimally invasive techniques. Once dealing with ureteric stones a number of factors may affect the choice of treatment e.g. type of stone, size of stone, site of impaction, position, patients preference and surgeons experience as well. ${ }^{10}$ Non operative methods of treating ureteric calculi include expectant management, use of drugs, or shock wave lithotripsy
(SWL). A number of drugs have been used in conservative/expectant management of stone disease e.g. calcium channel blockers, analgesics and alpha 1 blockers. Tamsulosin, an alpha 1 blocker, acts by relaxing ureteric smooth muscle and hence is very effective in expulsion of stones especially after SWL. In 2016, study conducted by Turk et al, showed the benefit of Tamsulosin as an adjunct to SWL in terms of reducing the requirement of analgesia. ${ }^{11}$ It also helps in accessing distal ureter once instruments are being used for stone removal, and at the same time also helps in stone expulsion and reduces complications. ${ }^{12-14}$ This is why; nowadays URS is recommended over conservative/ SWL for treating ureteric stones. Research shows that alpha blockers also reduce stent related urinary symptoms like pain during voiding and flank pain by relaxing bladder neck, thus improving quality of life. ${ }^{15,16}$

Our study clearly shows that the preoperative use of alpha blocker did result in reduced operative time and facilitated stone access as exhibited by lesser complications and ease of removal of stone in the study group "B". In 2013, a study was conducted by Ketabchi and Mehrabithat also revealed the same facts. ${ }^{17} \mathrm{~A}$ major difference between our study and the International studies was the fact that we did not consider dilatation of ureteric orifice as a separate study variable. In fact, all patients were subjected to hydrodilatation by saline irrigation. Our study was, however, double blinded and the surgeon did not know which patient was on pre-operative Tamsulosin. It was observed that in study group " $B$ " patients, identification of ureteric orifice was easy and introduction of ureteroscope was possible over a guidewire without any difficulty. This was most probably because of the smooth muscle relaxing action of Tamsulosin as evident from the results i.e. less time and reduced complications and higher success rate in group "B" patients. We did not use stenting as a routine in our patients. Stenting was done only in complicated cases like mucosal injury, abundant gravel and significant proximal dilatation.

In 2020, Tan et al, published an analytical study in which a pooled analysis of different studies was conducted between January 1980 and June 2019 to identify the effect of alpha-blockers as adjunctive therapy before URS for the treatment of ureteric calculi. When the results were compared with placebo group, which were very much comparable to our results, it was found that patients that received pre-treatment with alpha blocker had significantly less requirement for 
balloon dilatation, a significantly lower risk of complications, higher successful access to the stone and a significantly higher stone-free rate at the end of week 4. However, in this analysis, contrary to our findings, no significant difference in the operation time between the two groups was found. ${ }^{18}$

In 2018, Mohey et al, published a study, ${ }^{19}$ that showed the results that were comparable to ours in which pre-operative alpha blockade was achieved with $8 \mathrm{mg}$ of Silodosin. During URS, the group that received Silodosin was found that advancement of ureteroscope was much easier which made access to the stone also easier. As a result of this, the duration of procedure was shortened with lower incidence of complications. Post-operatively also, higher stone free rate was achieved and the need for analgesia was also minimal as compared to the placebo group. ${ }^{19}$

However, there is evidencepublished by Sokhal et $a l$, that does not favour the use of alpha blocker prior to URS. A study used Tamsulosin $0.4 \mathrm{mg}$ in one of the two groups of a case control study before URS in patients with mid and lower ureteric calculi. Peroperatively, no technical ease was found in terms of passing ureteroscope, access to the stone or lowering the rate of complications as compared to the group that did not receive pre-treatment alpha blockade. ${ }^{20}$ One reason for such conclusion can be that in our study the duration of pre-treatment with alpha blocker was 7 days however, in the study just mentioned this duration was only 3 days. This might be the factor for not achieving the desired effects of technical ease.

\section{CONCLUSION}

Alpha blockers do have a role once used before URS. It reduces complications, decreases operative time and makes the procedure easier and safer to perform and thus causes less morbidity. To define the definite guidelines in this regard, still large multicentre studies have to be conducted.

\section{Conflict of Interest: None.}

\section{Authors' Contribution}

AN: Operating surgeon, NA: Design, NA: Interpretation of data, YSK: Conception, IR: Analysis, MZA: Interpretation of data.

\section{REFERENCES}

1. Hollingsworth JM, Canales BK, Rogers MA, Sukumar S, Yan P, Kuntz GM, et al. Alpha blockers for treatment of ureteric stones: systematic review and meta-analysis. BMJ 2016; 355: i6112.

2. Hofmann R. Ureterorenoskopie (URS) beiHarnsteinen [Ureteroscopy (URS) for ureteric calculi]. Urolog A 2006; 45(5): 637-646

3. Abdelaziz AS, Kidder AM. Tamsulosin therapy improved the outcome of ureterorenoscopy for lower ureteral stones: A pros- pective, randomised, controlled, clinical trial. Afr J Urol 2017; 23(2): 148-153.

4. Tanriverdi O, Silay MS, Kadihasanoglu M, Aydin M, Kendirci M, Miroglu C. Revisiting the predictive factors for intra-operative complications of rigid ureteroscopy: a 15-year experience. Urol J 2012; 9(2): 457-464.

5. Hollingsworth JM, Rogers MA, Kaufman SR, Bradford TJ, Saint S, Wei JT, et al. Medical therapy to facilitate urinary stone passage: a meta-analysis. Lancet 2006; 368(9542): 1171-1179.

6. Bader MJ, Eisner B, Porpiglia F, Preminger GM, Tiselius HG. Contemporary management of ureteral stones. Eur Urol 2012; 61(4): 764-772.

7. Zhang MY, Ding ST, Lü JJ, Lue YH, Zhang H, Xia QH. Comparison of tamsulosin with extracorporeal shock wave lithotripsy in treating distal ureteral stones. Chin Med J (Engl) 2009; 122(7): 798-801.

8. Ketabchi AA, Mehrabi S. The effect of tamsulosin, an alpha-1 receptor antagonist as a medical expelling agent in success rate of ureteroscopic lithotripsy. Nephrourol Mon 2013; 6(1): e12836.

9. Badran YA, Ali TA, Elaal MA, Ali M, Jamal A, AbdulallAF. Role of tamsulosin oral control absorption system and alfuzosin in shock wave lithotripsy for renal and upper ureteric calculi. J Am Sci 2013; 9(6): 387-393.

10. Griwan MS, Singh SK, Paul H, Pawar DS, Verma M. The efficacy of tamsulosin in lower ureteral calculi. Urol Ann 2010; 2(2): 6366.

11. 11.Türk C, Petř́k A, Sarica K, Seitz C, Skolarikos A, Straub M, et al. EAU Guidelines on Diagnosis and Conservative Management of Urolithiasis. Eur Urol 2016; 69(3): 468-474.

12. Gravina GL, Costa AM, Ronchi P, Galatioto GP, Angelucci A, Castellani D, et al. Tamsulosin treatment increases clinical success rate of single extracorporeal shock wave lithotripsy of renal stones. Urol 2005; 66(1): 24-28.

13. Singh SK, Pawar DS, Griwan MS, Indora JM, Sharma S. Role of tamsulosin in clearance of upper ureteral calculi after extracorporeal shock wave lithotripsy: a randomized controlled trial. Urol J 2011; 8(1): 14-20.

14. Sayed MA, Abolyosr A, Abdalla MA, El-Azab AS. Efficacy of tamsulosin in medical expulsive therapy for distal ureteral calculi. Scand J Urol Nephrol 2008; 42(1): 59-62.

15. Wang CJ, Huang SW, Chang CH. Effects of tamsulosin on lower urinary tract symptoms due to double-J stent: a prospective study. Urol Int 2009; 83(1): 66-69.

16. Lamb AD, Vowler SL, Johnston R, Dunn N, Wiseman OJ. Metaanalysis showing the beneficial effect of a-blockers on ureteric stent discomfort. BJU Int 2011; 108(11): 1894-1902.

17. Ketabchi AA, Mehrabi S. The effect of tamsulosin, an alpha-1 receptor antagonist as a medical expelling agent in success rate of ureteroscopic lithotripsy. Nephrourol Mon 2013; 6(1): e12836.

18. Tan H, Li Y, Zhang X, Mao X. Pooled analysis of the efficacy and safety of adjunctive alpha-blocker therapy before ureteroscopy in the management of ureteral stones. J Int Med Res 2020; 48(6): 300060520923878.

19. Mohey A, Gharib TM, Alazaby H, Khalil M, Abou-Taleb A, Noureldin YA. Efficacy of silodosin on the outcome of semi-rigid ureteroscopy for the management of large distal ureteric stones: blinded randomisedtrial. Arab J Urol 2018; 16(4): 422-428.

20. Sokhal AK, Singh K, Goel S, Kumar M, Purkait B, Sain DK, et al. Do preoperative alpha blockers facilitate ureteroscope insertion at the vesico-ureteric junction? an answer from a prospective case-controlled study. Eur Med J 2017; 2(3): 82-86. 